Volume 7 Issue 22009

Californian Journal of Health Promotion

Table of Contents

Content

CJHP Editorial Board

$\underline{\text { Pages }}$

Table of Contents

i-iv

Editorial

v-vi

vii

\title{
RESEARCH AND THEORY
}

Associations between Leisure Activities and HIV Risk Behaviors

01-15 among Rural Migrants in Urban China

Xinguang Chen, Xiaoming Li, Bonita Stanton, Xiaoyi Fang, Danhua Lin, and Rong Ma

Micronesian Migrant Health Issues in Hawaii:

Part 1: Background, Home Island Data, and Clinical Evidence

Seiji Yamada and Ann Pobutsky

Micronesian and Marshallese Migrant Health in Hawaii: Part 2:

Results of a Health and Language Assessment

Ann M. Pobutsky, Dmitry Krupitsky, and Seiji Yamada

Traffic Crash Victimizations of California Children and

Teenagers by Drinking Over-21 Drivers

Mike Males

Factors associated with self-competence and quality of life in

Chinese-American children

Jyu-Lin Chen and Mary Ellen Wilkosz

Breaking Down the Silence: A Study Examining Patterns of Sexual Assault and Subsequent Disclosure among Ethnic Groups of Asian Pacific Islander College Women

Divya P. Shenoy, Rosalyn Neranartkomol, Monisha Ashok, Anne

Chiang, Amy G. Lam, and Sang Leng Trieu

Road traffic injuries and risk factors

Abdulbari Bener, Huseyin R. Burgut, Heba Sidahmed, Rama AlBuz,

Rahima Sanya, Waleed Ali Khan 
The Undermined Determinant of a College's Success: Health \& Wellness of a College Employee

Jagdish Khubchandani and Timothy R. Jordan

The Effects of Six Weeks of Balance and Strength Training on

111-122 Measures of Dynamic Balance of Older Adults

Christopher J. Knerl, Petra B. Schuler, Lemuel W. Taylor, Ludmila M. Cosio-lima, Karla A. Caillouet

\section{BRIEF REPORT}

Measuring the Infusion of Service-Learning on Student

123-128

Outcomes-The Service-Learning Self-Efficacy Scale on Program Planning Competencies (SL-SEPP)

$\mathrm{Su}-\mathrm{I} \mathrm{Hou}$

\section{WORK BY GRADUATE STUDENTS}

Sexual Health Variables and the Human Papillomavirus Vaccine: An Investigation of Predictors in a Female Collegiate Population. Victoria Barry, Shannon B. Myers, Amy E. Sgrenci, Megan Lavery, Deirdra Frum, Erin L. O'Hea 